\title{
The Awareness of English as a Lingua Franca (ELF) and How It Affects English Language Teaching (ELT)
}

\author{
Doctor Shafiq Banat \\ Assistant Professor in Applied linguistics, Department of English, Jerash University, Jordan
}

\begin{abstract}
Through this paper, and the various points that have been discussed, it is evident that the ELF awareness is a basic framework which could be used to interpret the beliefs, attitudes, and perspectives of stakeholders. Also, hopefully, this study should influence the principles by which learning activities and classroom practices are implemented. The paper argues that core considerations must be taken into cognizance, as reviewed below, in the perspective of raising ELF awareness while reviewing the place of including ELF awareness concerns and ideas into current curriculum designing and development in order to aid broader application and for maximal impact on the principles and practices that govern ELT within a globally integrative perspective.
\end{abstract}

Keywords: Curriculum, ELF awareness, ELT, principles and practices, stakeholders.

DOI: $10.7176 / \mathrm{JEP} / 10-29-04$

Publication date:October $31^{\text {st }} 2019$

\section{Introduction}

English as a lingua franca (ELF) refers to the way the English language has been used over centuries as an everyday medium of transmission and means of discourse between interlocutors, especially those who are from distinct first languages. ELF, based on functions, has also been directly linked to that form of discourse that is being used primarily in intercultural interactions, instead of viewing it from the formal perspective as per the native speakers' standards for acceptable English. On the other hand, English as a foreign language (EFL) seeks to meet the established standards and norms of native speakers. Also, it accords due prominence to the native cultural perspectives.

Lingual franca is not exactly a new phenomenon. They have existed for hundreds of years before civilization. However, ELF is regarded as a relatively new phenomenon in respect to the wide extent of its usage - whether in its function as a lingua franca or in the geography of its usage and coverage. For instance, in a routine ELF interaction, a Nigerian might be meeting a Turkish for a business roundtable meeting holding at Hong Kong. Or, a Colombian tourist seeking from a Irish local the way to the zoo.

As popularly believed and scholarly agreed, the rise and proliferation of wide-ranging technology since the late 20th century has provided an ease in great networks of instant, rapid global communication. Thereby, the dividing walls of time and distance have been sunken, and further altering the underlining structures and behaviors of societies and the nature and trend of globalization. Owing to the world turning fast into a global village via sophisticated interconnection, a mutual medium if transmission is hence sought for. Since the current century, English has solved this problem by emerging as the world lingua franca. Through colonial efforts, it has encroached into farthest ends of the earth. And as such, it has successfully become the language of international trading, academic instruction, business, as well as cross-cultural connectivity. Due to its far-reaching spread and function globally, the uniqueness of ELF stands above repudiation - other factors accounting to this distinctness include but are not limited to the high diversity which ELF possesses, plus, it has a peculiar participation from the native speakers of the English language.

There is a back and forth relationship between globalization and language. It occurs in such a way that each affect the other both ways. For instance, in the way that English has connected the rest of the world to the leading most industrial nation of the world which serves as the manufacturer of the world, China, just by facilitating business interaction, there has been a furtherance of the agenda of trading beyond borders and shores. When globalization has occurred, and technology has advanced, societies and communities undergo changes. This social and physical change impacts on language, the English language, major lingua franca. And as English make into more foreign boundaries and cultures, it is further remodified in such ways as would soothe the specific unique needs of the locals, as well as their international language needs. In other words, English encounters new communities and cultures, it is shaped and adapted by these encounters to be used by local communities for local and international communication. As a result, hybrid forms are produced which contain new words, or newer nuances attached to existing words. This circle further and further causes a change in the language structure.

Due to ELF occurrences, the number of people using English as a lingua franca has by large proportions exceeded those who are born speakers, this phenomenon is peculiar to the English language, it is not a regular fact of European languages. This further results in diverse people groups having a claim or ownership to the English language.

Another peculiarity to the use of English as a lingua franca surrounds the exact condition of usage. Speaking 
broadly, communication in ELF is more based on purpose as opposed to form. To rephrase that, greater priority is given to the place of efficient communication, which ensures the listener understands the import of what you saythe lesser priority goes to grammatical accuracy. Due to this style of usage, ELF discourses are more often than not hybrid English. Interlocutors, while communicating, veer into their first properties of their languages, sometimes they give in to code-switching around the linguistic forms that they understand.

Established by the 'Vienna-Oxford International Corpus of English' (VOICE) and additional research, the following features of ELF lexicogrammar have been identified (Cogo \& Dewey, 2006; Seidlhofer, 2006):

- shift in the use of articles (including some preference for zero articles), e.g., both companies have signed proposal on the project.

- invariant question tags as in you're very busy today, isn't it? (and use of other similar universal forms)

- treating 'who' and 'which' as interchangeable relative pronouns, as in the picture who or a person which

- $\quad$ shift of patterns of preposition use, for example we have to study about

- preference for bare and/or full infinitive over the use of gerunds, as in I'm looking forward to see you tomorrow

- extension to the collocational field of words with high semantic generality, for example take an operation

- increased explicitness, for example how long time instead of how long

- exploited redundancy, such as ellipsis of objects/complements of transitive verbs as in "I wanted to go with..." or "You can borrow..."

On the other hand, the above features are not necessarily constant or fixed rules. Relatively though, the use of the above forms of expressions have no direct effect on the communicative efficiency of an ELF discourse or setting.

Looking at whether ELF could be regarded as a linguistically neutral form of speech, which some scholars have argued for (House, 2002; 2003); yet others (Klimpfinger, 2005; Pölzl, 2005; Pölzl \& Seidlhofer, 2006; Meierkord, 2002) still maintain that the degree of first language influence by the speakers renders it non-neutral. For the most, ELF usage occurs amongst nonnative speakers; however, this datum has not established that native English speakers do not actively participate in the usage of ELF in routine discourse. On the other hand, in most cases, the native speakers will be the smaller portion of the discussers. While using ELF for everyday discourse, the emphasis is placed on communication strategies, not necessarily 'nativeness', which can lead to communicative situations where those English native speakers who are not familiar with ELF and/or intercultural communication are at a disadvantage because they do not know how to use English appropriately in these situations.

Since contemporary times, the term ELF "has emerged as a way of referring to communication in English between speakers with different first language" (Seidlhofer, 2005). Speaking based off of a loosely referenced sense, of every English-speaking person on earth, just about $25 \%$ only count for native or born speakers (Crystal, 2003), by implication, thus, most ELF discourse is being carried out by interlocutors whose first languages aren't English. Granting the reality that a larger number of native English speakers also engage in the use of ELF for daily interactions both online and offline, in order words, since ELF is not associated only with foreign English users, a quite spectacular characteristic which sets the ELF apart is the fact that, more often than not, up until currently, English as a lingua franca is used as 'a 'contact language.' It provides a bridge of transmission and a medium of communication between persons and amongst groups of varying nationalities, cultures, and sociocultural perspectives, experiences, and exposures, the common ground for unity being the fact that English seems to be their lingua franca or official medium or language (Firth, 1996).

In some places, English has been embraced as the proper medium of transmission and instruction. In yet other places, there has been a sharp disapproval of the language. However, this notwithstanding, the fact remains that no one can repudiate the global reach, spread, and usage of the language. What may or may not, however, be subject to varying opinions is whether the boundaries and new thresholds of the language is being fashioned more by foreign users, due to its transnational and global use. In the very least, we can all come to the resolution that English as a language is equally influenced by both parties - foreign and native users alike. The unintended and unhindered consequence of this ongoing phenomenon, an ironic one at that, is that, as the vast populace of English users aren't native born ones, to whom English suffices as a nonnative speech form, the greater bulk of spoken conversations in English do not consist of any natural users of the language at all. Contrariwise though, there is still a propensity for native speakers to be considered as who draw the lines between acceptable usage and what is not. Accordingly, in view of ensuring that the notion and model of ELF enjoys recognition together with the native form of English, many researchers and scholars have voiced why the framework and perspective of ELF must be systematically examined and surveyed — ranging from issues regarding its form, usage, principles, and practices as well as attention paid toward how any frameworks created for ELF, whether existing or future works, will 
impact on how ELF is taught and learn within the classroom condition.

Due to the recent decades when English became a global language, there has been the need to study the way users who possess the English language as a lingua franca use it in communication - especially with other speakers with whom they do not have the same native language together (for instance, Cogo and Dewey, 2012). In order to carry this out, a useful resource that was turned to were the various forms of ELF found (such as: VOICE, ELFA, ACE). Notably among others, this study provides ample perspective into the world of these speakers, mainly the speech they use, plus, the possible ways they are able to use both English and their native language-also, with the ways they employ in order to have others grasp the meaning of their communication, whether those of English origin or not (Jenkins, 2015; Mauranen, 2012; Seidlhofer, 2011).

Since the inception of the study of English as a lingua franca, its scholars attempted to define and explain the concept. However, the more studies were conducted was the more it became obvious that ELF cannot be studied properly without attention given to the English language teaching classroom. And the goal was to better assist foreign English speakers in developing the utmost fluency and confidence while communicating. Also, in the long run, stakeholders in the teaching of the English language who may exist and function in their various capacities, such as teacher educators, assessment specialists, designers of syllabuses and programs of study, as well as policy makers, could begin to include ELF in their evaluation framework for both principles governing the current system, and as well, be inventive in the way that instruction, assessment and policies are being carried out (i.e., practices.). Thus, in a nutshell, findings from ELF studies and surveys could go a long way in advancing the principles and practices of the English language teaching.

This proposed model, however, does not promise an easy process though. It comes with its own complexities. The attempt to merge two multipart phenomena cannot come to light without confronting responses from the stakeholders as well as existing models and practices. Hereunder is the presentation of a perspective (awareness of the ELF) that might serve as a guide on how to integrate both systems - ELF and ELT. We will commence with the meaning of ELF awareness and then examine its mechanisms: awareness of language and language use, awareness of instructional practice, and awareness of learning.

\section{The Meaning of ELF and its Awareness}

Basically, when two parties of different native languages communicate, the form of communication that is produced in their dialogue is what we may refer to as English as a lingua franca. Going by this view, we can infer that, based on conventional situation, ELF operates in linguistically and culturally diverse backgrounds. Also, with this in mind, we must sever it from the ties that bound the standard use of the English language (Cogo and Jenkins, 2010; Seidlhofer, 2010).

The overarching element of the English language spoken as a lingua franca is the fact that it is all-embracing and stretchy, when it comes to language form, pragmatics, and culture. In this regard, it is malleable in that it provides a means of transmission that is flexible and adaptable by a speaker during a discourse (Jenkins, 2015; Mauranen, 2012; Seidlhofer, 2011). This, as such, drags the spotlight directly on the conditions individual interaction, not necessarily on language per se. The interacting parties and social reasons and factors surrounding each discourse becomes the epicenter (Kalocsai, 2014; Seidlhofer, 2011).

To be clear, ELF is no simple area of study, nor can it be easily put in a single sentence of definition. Yet the very import of this study is that ELF awareness functions as a gateway of insight into teaching and learning, plus other stakeholders of English language teaching mentioned earlier. And the premise for this choice, ELF instead of other branches of studies of the English language, is that, while different foreign speakers who have come from various first language backgrounds might endeavor to master the language to a commendable level of fluency, we can still find areas where they have core personal rational and interaction needs, especially while using the language as their major medium of transmission. This premise is the basis for linking both ELF and ELT.

According to Seidlhofer (2011), depending on what stakeholder is in the picture, ELF awareness might take a new practice or cover different latitude. As ELF scholars Sifakis and Bayyurt (2017) have put forth: for a teacher, for instance, the meaning of ELF awareness would bother around ways of studying and comprehending ELF related principles and subjects in order to adapt the ideas to their core practices while executing the learning curriculum, plus, to integrate the new ideas into one's classroom and teaching experience, while giving attention to the dynamics surrounding its use, application, and development within their local learning scope and context. With the forgoing in mind, let us review the three main elements which to give focus to in the bid to develop a greater sense and awareness of ELF.

1. Awareness of Language and Language Use. People learning the English language at some point rise to the consciousness of how that in using the English language as a lingua franca, there are some obvious variations between the features of their discourse and those exhibited by native speakers of English. An underlying element responsible for this variation is that the former uses the English language more from a conscious level, while the latter engages their language from a more subliminal state of mind (Schmidt, 1994). 
2. Awareness of Instructional Practice. Because the crux of our study is about applying ELF idea to improve instructional practices and classroom learning contexts, one major factors to take to mind is the practices surrounding how a teacher executes their job. This stems from the personal beliefs and notions a teacher has about the ways they should carryout teaching, whether or not they will evaluate certain areas of learning, plus, if they will or not respond to certain needs of their students, etc. Also, if ELF ideas must be integrated into the mainstream instructional practices, and if teachers are regarded as the primary agents or stakeholders of ELF awareness, then, by all means, their various sentiments, perceptions, and attitudes regarding teaching English must be considered. (Lyster and Saito, 2010).

3. Awareness of Learning. How does the use of English as a lingua franca impact on learning? The more folks engage the English language for the bulk of their social interactions, physically or on the internet, and the more they see it as their primary medium of interaction while interacting within the civilized and globalized world is the more that English feels natural, and not foreign just as some other language might feel alien to them (Ehlich, 2009). This phenomenon must be taking into core consideration in ELF awareness.

Given these factors, a teacher that thinks progressively about the ways ELF awareness might affect everyday communication as well as the way teaching English to international students can be carried out will consider the below objectives.

a. Teachers who are continually open to new ideas and new studies which stimulate them towards contemplating on the various densities and intricacies involved in the use of English language as transmission medium across societal and cultural borders.

b. Teachers who have also come to terms about the difficulties which older models that paid lesser regard to ELF awareness present while carrying out their teaching.

c. Teachers who are also involved in the planning and development curriculum design and implementation, especially coming up with models that are both realistic and current, as well as practicable.

\section{Conclusions}

Through this paper, and the various points that have been discussed, it is evident that the ELF awareness is a basic framework which could be used to interpret the beliefs, attitudes, and perspectives of stakeholders. Also, hopefully, this study should influence the principles by which learning activities and classroom practices are implemented.

\section{References}

Cogo, A. and Dewey, M. (2006). Efficiency in ELF communication. Nordic Journal of English studies.

Cogo, A. and Dewey, M. (2012). Analyzing English as a lingua franca. London: Continuum.

Cogo, A. \& Jenkins, J. (2010). 'English as a lingua franca in Europe: a mismatch between policy and practice.' European Journal of Language Policy.

Crystal, D. (2003). English as a Global Language (Second edition). Cambridge: Cambridge University Press.

Ehlich, K. (2009). 'What makes a language foreign?' berlin: De Gruyter.

Firth, A. (1996). 'The discursive accomplishment of normality. On "lingua franca" English and conversation analysis'. Journal of Pragmatics 26: 237-59.

House, J. (2002). Developing pragmatic competence in English as a Lingua Franca. Frankfurtam Main: Peter.

House, J. (2003). English as a lingua franca: A threat to multilingualism?. Journal of sociolinguistics.

Jenkins, J. (2015). 'Repositioning English and Multilingualism in English as a lingua franca.' Englishes in Practice, 2/3: 49-85.

Kalocsai, K. (2014). Communities of Practice and English as a Lingua Franca. Berlin: De Gruyter Mouton.

Klimpfinger, T. (2005). "The role of speakers' first and other languages in English as a lingua franca talk." Unpublished MA Thesis, University of http://www.univie.ac.at/voice/page/abstracts/klimpfinger_2005.pdf.

Lyster, R. and Saito, K. (2010). 'Oral feedback in classroom SLA: a meta-analysis.' Studies in Second Language Acwuisition.

Mauranen, A. (2012). Exploring ELF. Academic English Shaped by Non-native Speakers. Cambridge University Press.

Meierkord, C. (2002). "'Language stripped bare' or 'linguistic masala'? Culture in lingua franca conversation." In: Knapp, Karlfried; Meierkord, Christiane (eds.). Lingua franca communication. Frankfurt: Peter Lang, $109-133$.

Pölzl, U. (2005). "Exploring the third space. Negotiating culture in English as a lingua franca." Unpublished PhD thesis, University of Vienna

Pölzl, U. \& Seidlhofer, B. (2006). "In and on their own terms. The 'habitat factor' in English as a lingua franca interactions." International Journal of the Sociology of Language 177, 151-17. 
Schmidt, R. (1994). 'Implicit learning and the cognitive unconscious: Of artificial grammars and SLA.' San Diego: Academic Press.

Seidlhofer, B. (2005). Key Concepts in ELT: English as a Lingua Franca. Oxford: Oxford University Press.

Seidlhofer, B. (2006). Towards making 'Euro-English' a linguistic reality. London: Routledge.

Seidlhofer, B. (2010). 'Lingua franca English: The European context.' London: Routledge.

Seidlhofer, B. (2011). Understanding ELF. Oxford: Oxford University Press.

Sifakis, N.C. and Bayyurt, Y. (2017). 'ELF-aware teacher education and development.' London: Routledge. 